\title{
Estimation of spatial and temporal changes in net primary production based on Carnegie Ames Stanford Approach (CASA) model in semi-arid rangelands of Semirom County, Iran
}

\author{
Fatemeh HADIAN $^{1}$, Reza JAFARI ${ }^{1 *}$, Hossein BASHARI ${ }^{1}$, Mostafa TARTESH ${ }^{1}$, Kenneth D \\ CLARKE $^{2}$ \\ ${ }^{1}$ Department of Natural Resources, Isfahan University of Technology, Isfahan 8415683111, Iran; \\ ${ }^{2}$ School of Biological Sciences, University of Adelaide, South Australia 5005, Australia
}

\begin{abstract}
Net primary production (NPP) is an indicator of rangeland ecosystem function. This research assessed the potential of the Carnegie Ames Stanford Approach (CASA) model for estimating NPP and its spatial and temporal changes in semi-arid rangelands of Semirom County, Iran. Using CASA model, we estimated the NPP values based on monthly climate data and the normalized difference vegetation index (NDVI) obtained from the MODIS sensor. Regression analysis was then applied to compare the estimated production data with observed production data. The spatial and temporal changes in NPP and light utilization efficiency (LUE) were investigated in different rangeland vegetation types. The standardized precipitation index (SPI) was also calculated at different time scales and the correlation of SPI with NPP changes was determined. The results indicated that the estimated NPP values varied from 0.00 to $74.48 \mathrm{~g}$ $\mathrm{C} /\left(\mathrm{m}^{2} \cdot \mathrm{a}\right)$. The observed and estimated NPP values had different correlations, depending on rangeland conditions and vegetation types. The highest and lowest correlations were respectively observed in Astragalus spp.-Agropyron spp. rangeland $\left(R^{2}=0.75\right)$ with good condition and Gundelia spp.-Cousinia spp. rangeland $\left(R^{2}=0.36\right)$ with poor and very poor conditions. The maximum and minimum LUE values were found in Astragalus spp.-Agropyron spp. rangeland $(0.117 \mathrm{~g} \mathrm{C} / \mathrm{MJ})$ with good condition and annual grassesannual forbs rangeland $(0.010 \mathrm{~g} \mathrm{C} / \mathrm{MJ})$, respectively. According to the correlations between SPI and NPP changes, the effects of drought periods on NPP depended on vegetation types and rangeland conditions. Annual plants had the highest drought sensitivity while shrubs exhibited the lowest drought sensitivity. The positive effects of wet periods on NPP were less evident in degraded areas where the destructive effects of drought were more prominent. Therefore, determining vegetation types and rangeland conditions is essential in NPP estimation. The findings of this study confirmed the potential of the CASA for estimating rangeland production. Therefore, the model output maps can be used to evaluate, monitor and optimize rangeland management in semi-arid rangelands of Iran where MODIS NPP products are not available.
\end{abstract}

Keywords: CASA; NPP estimation; light utilization efficiency; vegetation type; drought; rangeland condition; semiarid rangelands

Citation: Fatemeh HADIAN, Reza JAFARI, Hossein BASHARI, Mostafa TARTESH, Kenneth D CLARKE. 2019. Estimation of spatial and temporal changes in net primary production based on Carnegie Ames Stanford Approach (CASA) model in semi-arid rangelands of Semirom County, Iran. Journal of Arid Land, 11(4): 477-494. https://doi.org/10.1007/s40333-019-0060-3

*Corresponding author: Reza JAFARI (E-mail: reza.jafari@cc.iut.ac.ir)

Received 2018-01-13; revised 2018-08-02; accepted 2018-09-19

(C) Xinjiang Institute of Ecology and Geography, Chinese Academy of Sciences, Science Press and Springer-Verlag GmbH Germany, part of Springer Nature 2019 


\section{Introduction}

Solar radiation is used in photosynthesis to convert carbon dioxide and water into carbon compounds including glucose and cellulose (Lammers et al., 2017). Solar radiation is thus effectively stored in rangeland plants as the first trophic level of the food chain (Sainte-Marie et al., 2012). Net primary production (NPP) is defined as the amount of energy produced by plants minus the energy consumed through respiration ( $\mathrm{Lu}$ et al., 2015). It reflects the rate of carbon assimilation (Roxburgh et al., 2005) and contributes to maintaining carbon balance in an ecosystem. NPP is determined by factors such as solar energy, temperature (Dintwe and Okin, 2018) and precipitation (Zhang et al., 2017) and is positively affected by living organisms like microbial biomass (Schimel et al., 1994).

Since direct field measurements are time-consuming and costly, models based on carbon cycle and plant structures (e.g., Biogeochemical Cycles Model (BIOME-BGC) (Kimball et al., 1997) and Dynamic Global Phytogeography Model (DOLY) (Donmez et al., 2011)), or remote sensing models based on satellite imagery (e.g., Global Production Efficiency Model (GLO-PEM) (Goetz et al., 1999), Carnegie Ames Stanford Approach (CASA) (Biondini et al., 1998; Liang et al., 2015; Bao et al., 2016; Jay et al., 2016), Simple Diagnostic Biosphere Model (SDBM) (Kaminski et al., 2002), Simple Biosphere Model (SIB) (Lokupitiya et al., 2009), and Terrestrial Uptake and Release of Carbon (TURC) model (Xia et al., 2013)), are generally used to estimate the spatial and temporal changes in NPP.

Among the various remote sensing models (Ruimy et al., 1994; Sun et al., 2013), the CASA is a process-based model that uses remotely sensed data and climate data to estimate regional and global NPP based on light utilization efficiency (LUE), by simulating the exchange of carbon dioxide between the atmosphere and biosphere (Gao et al., 2013). Assessments of the CASA at regional and global scales have shown that the model can not only estimate NPP, but also examine the effects of land degradation at different stages on phenology (Dieguez and Paruelo, 2017; Rafique et al., 2017). LUE is defined as the photosynthetic efficiency of plants at converting solar radiation into organic matter (Zhang et al., 2015) and is affected by energy distribution. It is the main component of the CASA and determines the accuracy of the estimated NPP (Dong et al., 2015). The optimal LUE of plants is determined by their physiological and phenological conditions. Therefore, stresses in temperature and changes in soil moisture can decrease photosynthetic efficiency (Nemry et al., 1999). According to available evidence, LUE is maximized under optimal environmental conditions and may be influenced by factors including temperature, humidity, pests and diseases, soil nutrients, and genetic and morphological characteristics of plants like leaf area index (LAI). Hence, different plant types have different LUE values (Fischer et al., 2014), which are individually determined by the difference between the observed and estimated NPP (Yu et al., 2005).

Rangeland condition is defined as the current state of a particular vegetation community in comparison to some perceived potential (Stoddart et al., 1975), which plays an important role in determining NPP of different vegetation types in a rangeland. For instance, NPP may be decreased by livestock grazing and decreased with reduced leaf area (Yu et al., 2018). Plant-available soil moisture can be greatly reduced by soil degradation and erosion (Biondini et al., 1998). A number of investigations have suggested that drought, increased temperature, topography and livestock grazing greatly affect changes in NPP of rangeland ecosystem (Chen et al., 2012; Jiang et al., 2015; Sha et al., 2017). In many rangelands of semi-arid regions, precipitation is considered as a major determinant of plant production at different time scales. Due to changes in drought and precipitation patterns, large fluctuations in NPP can be observed in these areas (Jafari and Bakhshandehmehr, 2013). Studies on NPP are consequently important for natural resource management in rangelands. Population growth and land use changes lead to the degradation of rangelands, which in turn causes erosion, flooding and desertification, and ultimately decreases NPP levels at regional and global scales (Chen et al., 2017; Ardö et al., 2018). Currently, the four-factor approach is one of the most widely used methods for rangeland assessment and monitoring (Hadian et al., 2019), which categorizes the rangeland condition into four levels: good, fair, poor and very poor.

Due to topographic conditions and the presence of Alborz and Zagros mountain ranges, Iran has 
a diverse climate at the national scale, i.e., from hyper-arid to wet (Kehl, 2009). There are a wide range of vegetation types and rangeland conditions in the country. As a result, the NPP values change not only with time, but also with geographical and anthropogenic variations. These changes are more pronounced in semi-arid areas of Semirom County, Iran. In fact, because of topography and land use conditions, different vegetation types in semi-arid rangelands of Zagros have different NPP values. Drought periods also affect plant production (Khatibi et al., 2017), but these effects vary depending on plant species. Moreover, temperature fluctuations, caused by elevation levels in the area, directly affect the phenology and production of potential plants (Dannenberg et al., 2015).

In Iran, the most widely used technique for measuring the rangeland production is probably the double sampling technique (Bonham, 2013). However, despite its wide application, this groundbased technique can only provide detailed data at relatively fine scales and fails to adequately cover a large area that is necessary for rangeland measurement and monitoring. In addition, the current available satellite products of rangeland production such as MOD17A3H are labeled with "no data" or have zero values in most of the arid and semi-arid lands of Iran. To our knowledge, no studies have assessed the capability of remote sensing and modeling techniques for production mapping in the rangelands of Iran. Therefore, it is essential to examine the potential of models based on remotely sensed data in mapping and monitoring the production of rangelands. The specific aims of this research were: (1) to evaluate the capability of the CASA for NPP mapping across a range of different vegetation types in the semi-arid rangelands of Semiron County, Iran; (2) to analyze the spatial and temporal changes of NPP at a seasonal scale within a single year (2016); and (3) to monitor NPP changes at an annual scale from 2002 to 2016. In addition, since the levels and changes of NPP are affected by drought and wet periods, the trend of NPP changes in relation to precipitation was also investigated using the standardized precipitation index (SPI).

\section{Materials and methods}

\subsection{Study area}

The study area is located in the rangelands of Semirom County $\left(30^{\circ} 42^{\prime}-31^{\circ} 51^{\prime} \mathrm{N}, 51^{\circ} 03^{\prime}-51^{\circ} 17^{\prime} \mathrm{E}\right)$, Isfahan Province, Iran. This area has a semi-arid climate with mean annual precipitation of $420 \mathrm{~mm}$. Most of annual precipitation occurs in winter while less in summer. The available temperature records from 2002 to 2017 indicate the annual average temperature of $13.6^{\circ} \mathrm{C}$ (IRIMO, 2016). Altitude in the area is relatively high, ranging from 1707 to $4393 \mathrm{~m}$ a.s.l., with the peaks in the Zagros Mountains. Due to large altitudinal range and human activity influences, there are a large number of vegetation types and a range of conditions in the rangelands (Hadian et al., 2013). In recent years, grazing and other activities, such as the construction of the Hana Dam and land use changes, have degraded the existing rangelands, especially those around the agricultural lands in Semirom County. It has been reported that the amount of NPP in the study area ranges from 10.00 to $46.00 \mathrm{~g} \mathrm{C} /\left(\mathrm{m}^{2} \cdot \mathrm{a}\right)$, depending on the vegetation type and rangeland condition (Feizi, 2018).

\subsection{Field measurements}

We used the following equation to calculate the sampling area by taking into account the resolution $(250 \mathrm{~m} \times 250 \mathrm{~m})$ of the Moderate Resolution Imaging Spectroradiometer (MODIS).

$$
A=P \times(1+2 L) \text {, }
$$

where $A$ is the sampling area (m); $P$ is the pixel resolution (m) of the MODIS bands used for NDVI calculation $(250 \mathrm{~m} \times 250 \mathrm{~m})$; and $L$ is the acceptable error (pixel) (McCoy, 2005). The MODIS sensor obtains data at different spatial resolutions including 250 (bands 1-2), 500 (bands 3-7), and $1000 \mathrm{~m}$ (bands 8-36) with wavelengths from 0.41 to $14.40 \mu \mathrm{m}$.

The conditions of rangelands in Semirom County were evaluated using a four-factor method and related forms (Khaleghi and Aeinebeygi, 2016). In this method, rangeland condition was calculated as the sum of the scores of soil factor (0-20), vegetation cover (0-10), vegetation composition ( 0 $10)$, and plant vigor and vitality $(0-10)$. Scores of $<20,21-30,31-37,38-45$ and $>45$ indicate very poor, poor, fair, good and excellent conditions, respectively (Friedel, 1991). Accordingly, the 
conditions of rangelands in Semirom County were categorized as very poor, poor, fair, and good.

During the field investigation, we identified a total of 12 vegetation types. The Astragalus spp.Bromus spp. (As-Br.F and $A s-B r$.P) and Astragalus spp.-Daphne spp. (As-Da.F and $A s-D a . P)$ had two conditions including poor and fair in different parts of the study area. Thus, NPP was measured in 14 vegetation types (Table 1). A total of 30 sampling sites were designed for each vegetation type. Vegetation cover (in percentage) in an area of $500 \mathrm{~m} \times 500 \mathrm{~m}$ was determined using 8 plots (10 $\mathrm{m} \times 10 \mathrm{~m}$ for each) (Khajeddin, 1995) and the total production of all plant species was weighed in a $2 \mathrm{~m} \times 1 \mathrm{~m}$ quadrat (Fig. 1) (Yeganeh et al., 2014).

Table 1 Vegetation and rangeland characteristics of the study area

\begin{tabular}{|c|c|c|c|}
\hline Vegetation type & Acronym & Rangeland condition & Life form \\
\hline Annual grasses-annual forbs & An.gr-An.fo & Poor & Annual \\
\hline Artemisia aucheri & Ar.au & Poor & Bush \\
\hline Astragalus spp.-Acantholimon spp. & $A s-A c$ & Poor & Bush \\
\hline Astragalus spp.-Agropyron spp. & $A s-A g$ & Good & Bush-grass \\
\hline Astragalus spp.-Bromus spp. & $A s-B r . \mathrm{F}$ & Fair & Bush-grass \\
\hline Astragalus spp.-Bromus spp. & $A s-B r . \mathrm{P}$ & Poor & Bush-grass \\
\hline Astragalus spp.-Cousinia spp. & $A s-C o$ & Fair & Bush \\
\hline Astragalus spp.-Daphne spp. & $A s-D a . \mathrm{F}$ & Fair & Bush-shrub \\
\hline Astragalus spp.-Daphne spp. & $A s-D a . P$ & Poor & Bush-shrub \\
\hline Astragalus spp.-Psathyrostachys spp. & $A s-P s$ & Fair & Bush \\
\hline Daphne spp.-Astragalus spp. & $D a-A s$ & Poor & Shrub-bush \\
\hline Gundelia spp.-Cousinia spp. & $\mathrm{Gu}-\mathrm{Co}$ & Very poor & Bush \\
\hline Euphorbia spp.-Hertia spp. & $\mathrm{Eu}-\mathrm{He}$ & Poor & Bush \\
\hline Sophora spp.-Launaea spp. & So-La & Very poor & Bush \\
\hline
\end{tabular}

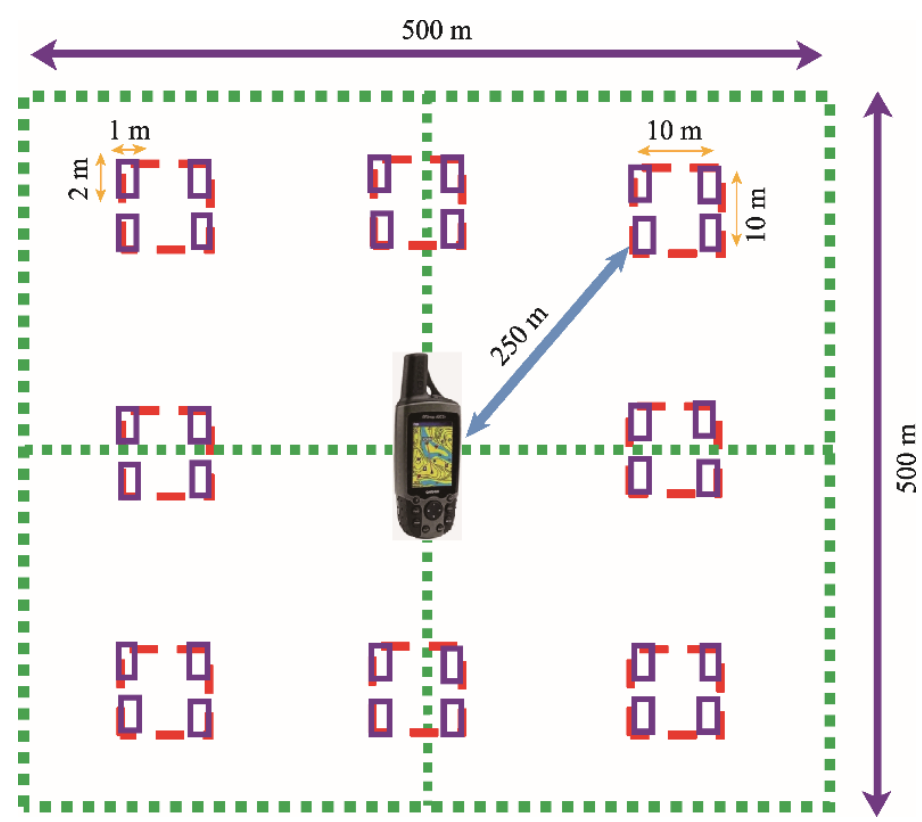

Fig. 1 Field measuring method

\subsection{Climate and satellite data}

Meteorological data including monthly temperature, precipitation and solar radiation during 20022016 were obtained from the regional meteorological offices of all weather stations in the study area. We used the Angstrom-Prescott equation to calculate the amount of solar radiation based on the total solar radiation recorded at the synoptic weather stations (Alamdari et al., 2013). The SPI 
was calculated with the SPIEXE program at 1-, 2-, 3-, 6-, 9- and 12-month intervals (ending in May of each year) during 2002-2016 for determining the effect of drought on vegetation growth (LloydHughes and Saunders, 2002; Ji and Peters, 2003). The NPP values at 30 sampling sites for each vegetation type and rangeland condition were separately averaged to compare with the annual SPI at 1-, 2-, 3-, 6-, 9- and 12-month intervals during the study period (Fig. 2).

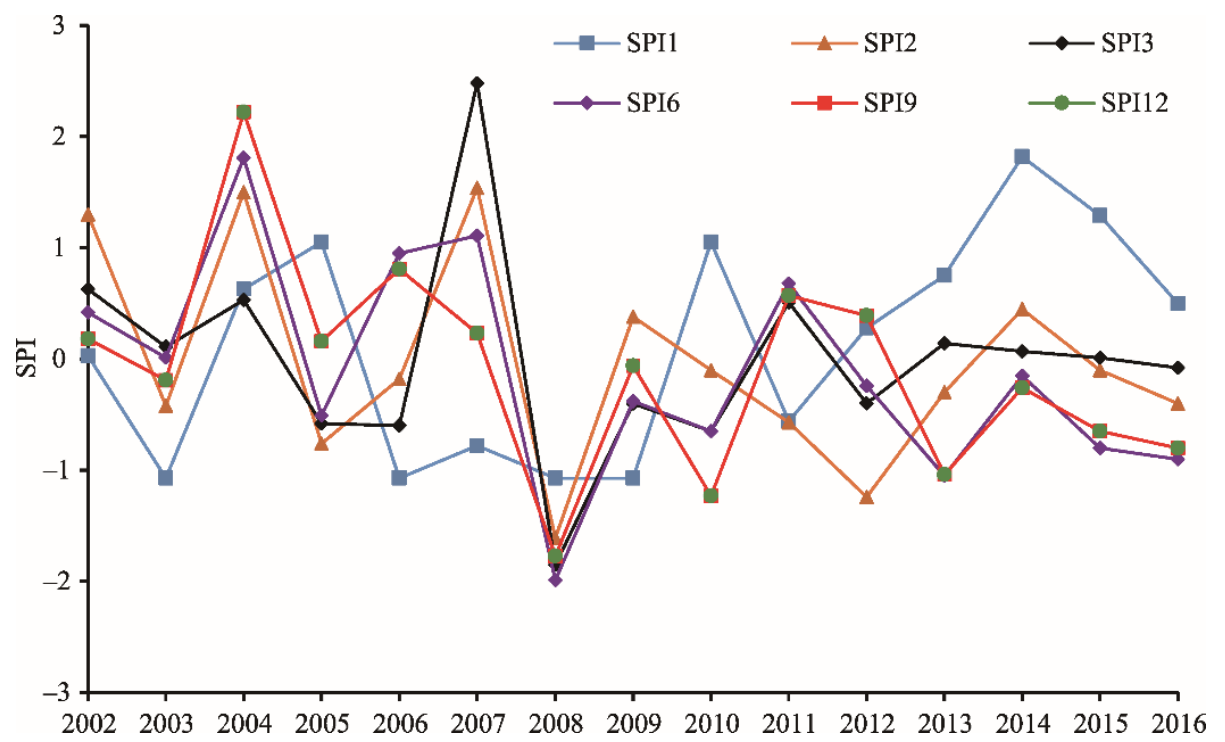

Fig. 2 Annual standardized precipitation index (SPI) values at different time scales (1-, 2-, 3-, 6-, 9- and 12-month, corresponding to SPI1, SPI2, SPI3, SPI6, SPI9 and SPI12, respectively) during 2002-2016

Satellite data were extracted from NASA's Earth Observing System (EOS) and NASA's Land Processes Distributed Active Archive Center (LP DAAC) (https://earthexplorer.usgs.gov). The MODIS 16-day NDVI products were used to calculate the required parameters of the CASA. The seasonal variations of NPP from 21 March to 13 September in 2016 (Table 2) as well as the annual NPP values during 2002-2016 were estimated using the average of two MODIS 16-day NDVI products by the same method described by Yu et al. (2009) and Yuan et al. (2016).

Table 2 Acquisition dates from MODIS NDVI products in 2016

\begin{tabular}{ccccc}
\hline Image & Satellite & $\begin{array}{c}\text { Start date } \\
(\mathrm{dd} / \mathrm{mm} / \text { yyyy })\end{array}$ & $\begin{array}{c}\text { End date } \\
(\mathrm{dd} / \mathrm{mm} / \mathrm{yyyy})\end{array}$ & $\begin{array}{c}\text { Resolution } \\
(\mathrm{km})\end{array}$ \\
\hline MOD13Q1-NDVI & TERRA & $21 / 03 / 2016$ & $05 / 04 / 2016$ & 0.25 \\
MOD13Q1-NDVI & TERRA & $06 / 04 / 2016$ & $21 / 04 / 2016$ & 0.25 \\
MOD13Q1-NDVI & TERRA & $22 / 04 / 2016$ & $07 / 05 / 2016$ & 0.25 \\
MOD13Q1-NDVI & TERRA & $08 / 05 / 2016$ & $23 / 05 / 2016$ & 0.25 \\
MOD13Q1-NDVI & TERRA & $24 / 05 / 2016$ & $08 / 06 / 2016$ & 0.25 \\
MOD13Q1-NDVI & TERRA & $09 / 06 / 2016$ & $24 / 06 / 2016$ & 0.25 \\
MOD13Q1-NDVI & TERRA & $25 / 06 / 2016$ & $10 / 07 / 2016$ & 0.25 \\
MOD13Q1-NDVI & TERRA & $11 / 07 / 2016$ & $26 / 07 / 2016$ & 0.25 \\
MOD13Q1-NDVI & TERRA & $27 / 07 / 2016$ & $11 / 08 / 2016$ & 0.25 \\
MOD13Q1-NDVI & TERRA & $12 / 08 / 2016$ & $27 / 08 / 2016$ & 0.25 \\
MOD13Q1-NDVI & TERRA & $28 / 08 / 2016$ & $12 / 09 / 2016$ & 0.25 \\
MOD13Q1-NDVI & TERRA & $13 / 09 / 2016$ & $28 / 09 / 2016$ & 0.25 \\
\hline
\end{tabular}

\subsection{Estimation of NPP using the CASA model}

Climate factors (including precipitation, temperature and solar radiation), NDVI images, absorbed photosynthetically active radiation (APAR; $\mathrm{MJ} / \mathrm{m}^{2}$ ) at $400-700 \mathrm{~nm}$, and land use/land cover maps (Feizi, 2018) were used to simulate NPP by the CASA model (Hua et al., 2014). Since NPP values 
were different among vegetation types, the NPP was separately calculated for each vegetation type. The relationships between the observed and estimated NPP in the sampling sites were then evaluated using regression analysis and the coefficient of determination. Equations 2-16 were used in the CASA model and Figure 3 described the modelling process for estimating NPP.

$$
\begin{gathered}
\operatorname{NPP}(x, t)=\operatorname{APAR}(x, t) \times \varepsilon(x, t), \\
\operatorname{APAR}(x, t)=\operatorname{FPAR}(x, t) \times \operatorname{SOL}(x, t) \times 0.5,
\end{gathered}
$$

where NPP is the net primary production $\left(\mathrm{g} \mathrm{C} /\left(\mathrm{m}^{2} \cdot \mathrm{a}\right)\right)$; APAR is the absorbed photosynthetically active radiation $\left(\mathrm{MJ} / \mathrm{m}^{2}\right) ; \varepsilon$ is the light utilization efficiency $(\mathrm{g} \mathrm{C} / \mathrm{MJ})$; FPAR is the fraction of APAR $\left(\mathrm{MJ} / \mathrm{m}^{2}\right)$; and SOL indicates the total solar radiation $\left(\mathrm{MJ} / \mathrm{m}^{2}\right)$.

In the equations below, FPAR min $_{\text {in }}$ and FPAR $\max$ values are 0.001 and 0.950 , respectively (Potter et al., 1999). We obtained the amount of FPAR according to the following equations and the obtained $\alpha$ was 0.447 (the mean value of FPAR ${ }_{1}$ and FPAR 2 ) (Yu et al., 2009):

$$
\begin{aligned}
& \operatorname{FPAR}(x, t)=\mathrm{FPAR}_{1}+(1+\alpha) \mathrm{FPAR}_{2}, \\
& \operatorname{FPAR}_{1}(x, t)=\frac{\left[(\mathrm{NDVI})(x, t)-(\mathrm{NDVI})_{i, \text { min }}\right] \times\left(\mathrm{FPAR}_{\text {max }}-\mathrm{FPAR}_{\text {min }}\right)}{(\mathrm{NDVI})_{i, \text { max }}-(\mathrm{NDVI})_{i, \text { min }}}+\mathrm{FPAR}_{\text {min }} \text {, } \\
& (D)(x, t)=\left[\frac{(\mathrm{NDVI}-1)(x, t)}{(\mathrm{NDVI}+1)(x, t)}\right], \\
& \operatorname{FPAR}_{2}(x, t)=\frac{\left[(D)(x, t)-(D)_{i, \text { min }}\right] \times\left(\mathrm{FPAR}_{\text {max }}-\mathrm{FPAR}_{\text {min }}\right)}{(D)_{i, \text { max }}-(D)_{i, \text { min }}}+\mathrm{FPAR}_{\text {min }} \text {, } \\
& \varepsilon(x, t)=T_{\varepsilon 1}(x, t) \times T_{\varepsilon 2}(x, t) \times W_{\varepsilon}(x, t) \times \varepsilon_{\max }, \\
& T_{\varepsilon 1}(x, t)=0.8+0.02 T_{\mathrm{opt}}(x)-0.0005 \times\left[T_{\mathrm{opt}}(x)\right]^{2}, \\
& T_{\varepsilon 2}(x, t)=\frac{1.184}{\left\{1+\exp \left[0.2 \times\left(T_{\mathrm{opt}}(x)-10-T(x, t)\right)\right]\right\} \times 1 /\left\{1+\exp \left[0.3 \times\left(-T_{\mathrm{opt}}(x)-10-T(x, t)\right)\right]\right\}}, \\
& W_{\varepsilon}=0.5+0.5 \times \frac{E(x, t)}{E_{P}(x, t)}, \\
& E(x, t)=\left\{P \times R(x, t) \times\left[P^{2}+(R(x, t))^{2}+P \times R(x, t)\right]\right\} /\left\{[P \times R(x, t)] \times\left[P^{2} \times R(x, t)\right]\right\}, \\
& E_{P}(x, t)=\left[E(x, t)+E_{0}(x, t)\right] / 2, \\
& E_{0}(x, t)=16 \times[10 \times T(x, t) / I(x)]^{a(x)}, \\
& a(x)=\left(0.651 \times I(x)^{3}-77.1 \times I(x)^{2}+17920 \times I(x)+492390\right) \times 10^{-6} \text {, } \\
& I(x)=\sum_{i=1}^{12}\left(\frac{T_{a i}}{5}\right)^{1.514},
\end{aligned}
$$

where $D$ is a coefficient extracted from NDVI; $\varepsilon$ is the light utilization efficiency $(\mathrm{g} \mathrm{C} /(\mathrm{MJ}))$ and $\varepsilon_{\max }$ represents the radiation power at maximum APAR $(\mathrm{g} \mathrm{C} / \mathrm{MJ}) ; T_{\varepsilon 1}$ is the temperature $\left({ }^{\circ} \mathrm{C}\right)$ at which the plant can perform photosynthetic activities; $T_{\varepsilon 2}$ is the temperature $\left({ }^{\circ} \mathrm{C}\right)$ at which the plant can efficiently use the light; $W_{\varepsilon}$ is the water stress coefficient $(\mathrm{Ks})$, which determines the moisture level affecting the efficient use of radiation and depends on the plant's ability to maintain soil moisture $(\mathrm{mm}) ; T_{\text {opt }}$ is the monthly temperature $\left({ }^{\circ} \mathrm{C}\right)$ when the NDVI reaches its highest value in a certain area in one year; $E, E_{p}$, and $E_{0}$ represent the regional, potential, and local potential evapotranspiration $(\mathrm{mm})$, respectively; $R$ is the net solar radiation $\left(\mathrm{W} / \mathrm{m}^{2}\right) ; I$ is the annual heat index (Rohli and Vega, 2013); and $T_{a i}$ is the monthly temperature, when the air temperature ranges from $0.0^{\circ} \mathrm{C}$ to $26.5^{\circ} \mathrm{C}$. After calculating the above-mentioned parameters, the NPP maps of the study 
area were produced and then the slope of NPP $\left(\mathrm{g} \mathrm{C} /\left(\mathrm{m}^{2} \cdot \mathrm{a}\right)\right)$ changes during 2004-2007 (the wet period) and 2013-2016 (the drought period) was determined using the following equation (Zhou et al., 2015):

$$
\text { Slope }=\frac{n \times \sum_{i}^{n} i \times \mathrm{NPP}_{i}-\left(\sum_{i}^{n} i \times \mathrm{NPP}\right)}{n \times\left(\sum_{i}^{n} i\right)^{2}-\left(\sum_{i}^{n} i\right)^{2}},
$$

where $n$ is the interval studied and $i$ shows the year number (i.e., 1 for the first year, 2 for the second year, and so on).

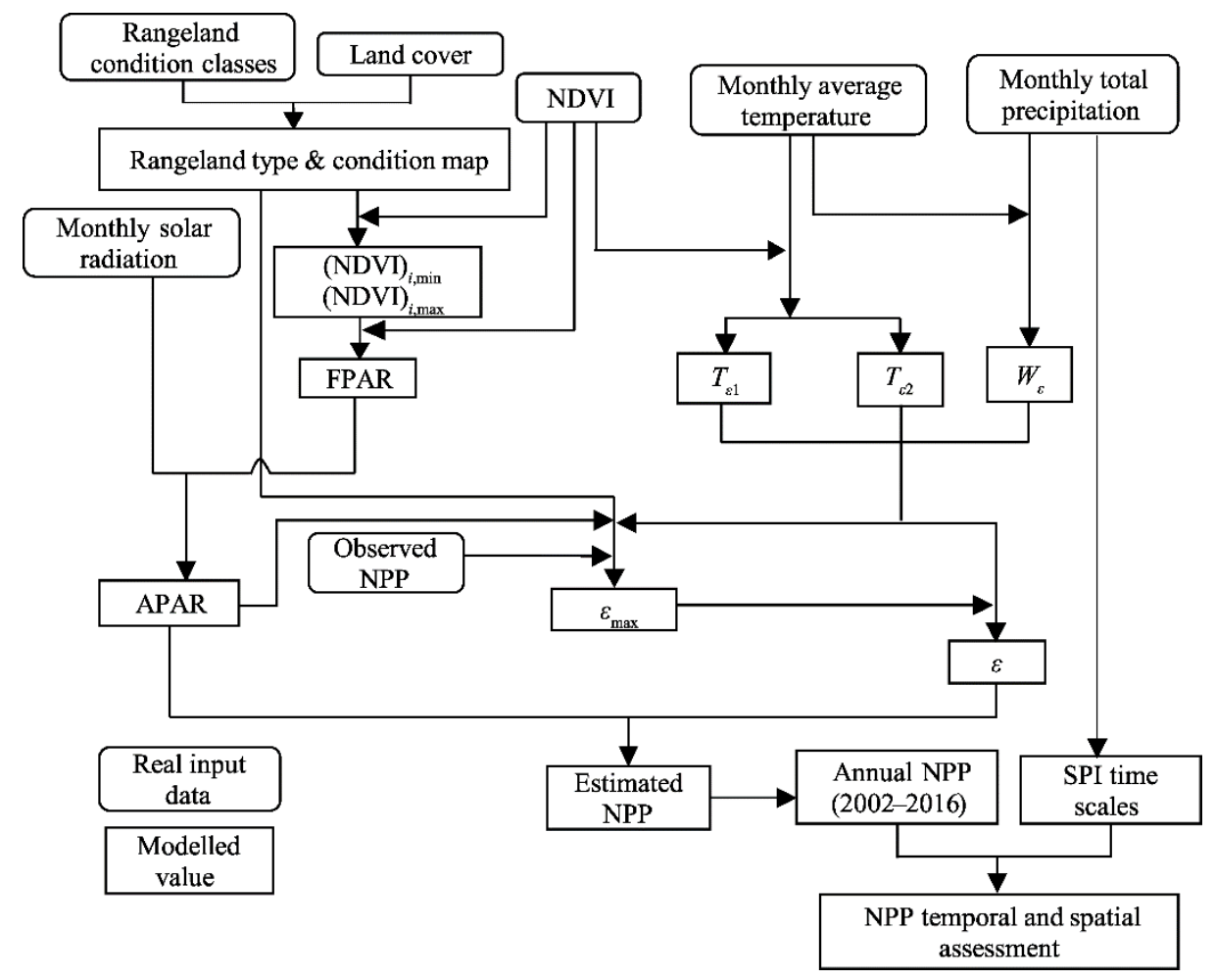

Fig. 3 Net primary production (NPP) modeling based on Carnegie Ames Stanford Approach (CASA) model. NDVI, normalized difference vegetation index; APAR, absorbed photosynthetically active radiation; FPAR, fraction of APAR; SPI, standardized precipitation index; $T_{\varepsilon 1}$, the temperature at which the plant can perform photosynthetic activities; $T_{\varepsilon 2}$, the temperature at which the plant can efficiently use the light; $W_{\varepsilon}$, the water stress coefficient; $\varepsilon \max$, radiation power at maximum APAR; $\varepsilon$, light utilization efficiency.

\subsection{Light utilization efficiency(LUE) calculation}

In this study, we determined LUE based on thermodynamic laws and the ratio of the NPP to the APAR (Eq. 18). The LUE value was considered as the slope of the line in the regression relationship between APAR $(x)$ and observed NPP $(y)$ (Pan et al., 2009).

$$
\mathrm{LUE}=\frac{\mathrm{NPP}}{\mathrm{APAR}} \text {. }
$$

\section{Results}

\subsection{Assessment of the CASA model and estimation of NPP}

The evaluation of the CASA model in different vegetation types revealed lower annual NPP values in rangelands with poor and very poor conditions than in those with good and fair conditions. Except for the rocky areas in the southern parts of the study area, the annual NPP values were lower 
and the level of degradation was higher in areas with lower altitudes. Agricultural lands and areas around Semirom County exhibited low NPP values, possibly due to rangeland degradation.

Data on harvested plants in each vegetation type (measured at 30 sampling sites) were used to evaluate the efficiency of the CASA in NPP estimation. Observed and estimated NPP values were significantly correlated $\left(R^{2}=0.95\right.$; Fig. $\left.4 \mathrm{a}\right)$, indicating that the CASA model was capable of predicting almost all of the variations in NPP across the sampling sites. Despite a wide range of vegetation types and different dominant plant species in the region, correlations between observed and estimated NPP values for all rangeland conditions (very poor to good) were significant at the 0.01 significance level $\left(R^{2}\right.$ values of $\left.0.36-0.80\right)$. In general, the estimated NPP values in the region ranged between 0.00 and $74.48 \mathrm{~g} \mathrm{C} /\left(\mathrm{m}^{2} \cdot \mathrm{a}\right)$ in 2016 (Fig. $\left.4 \mathrm{~b}\right)$.
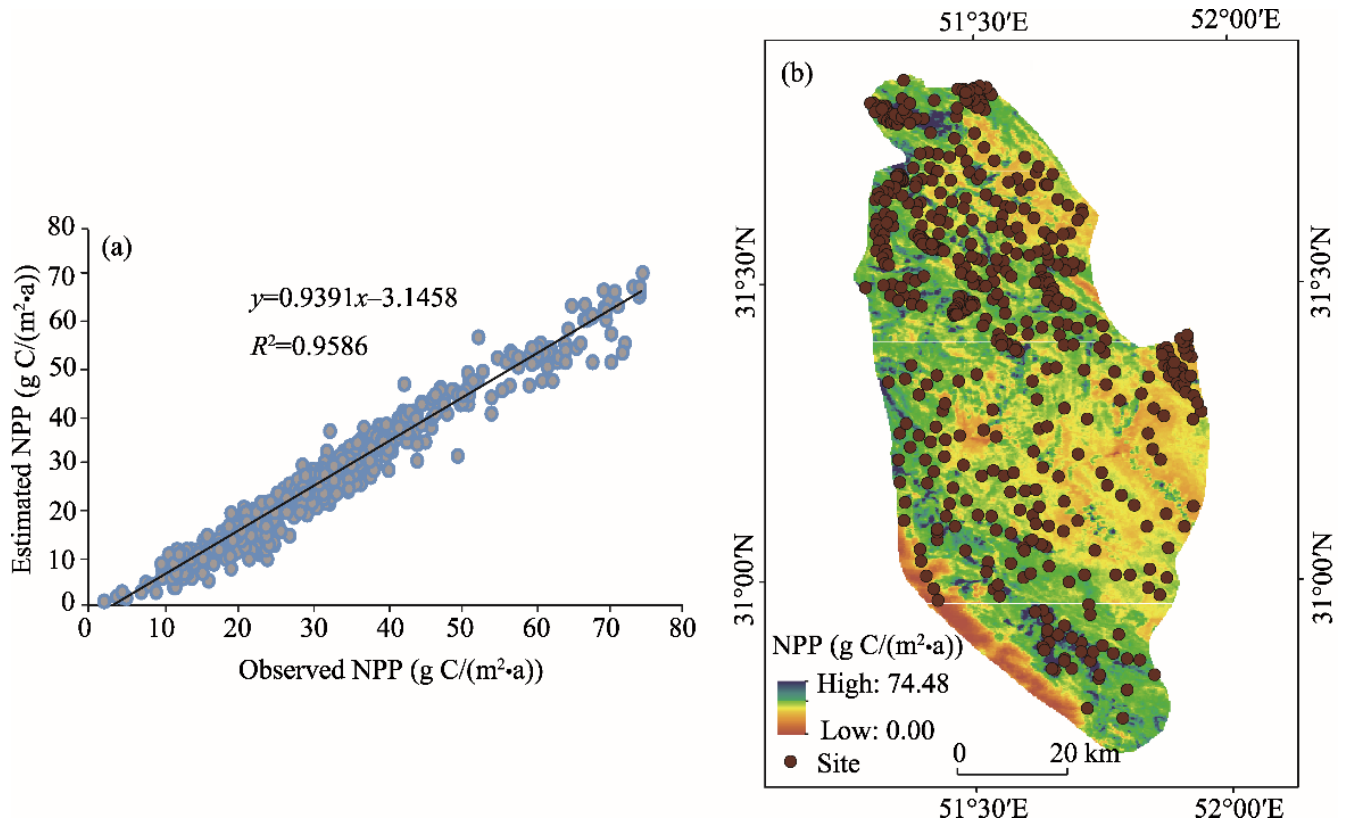

Fig. 4 Correlation between observed and estimated NPP values (a) and the spatial distribution map of estimated NPP and field sampling sites (b) in 2016

Observed NPP values of 37.00 and $34.00 \mathrm{~g} \mathrm{C} /\left(\mathrm{m}^{2} \cdot \mathrm{a}\right)$ were recorded in $A s-B r$ vegetation type with fair and poor conditions, respectively. The Astragalus spp.-Agropyron spp. (As-Ag) vegetation type showed the highest amount of NPP $\left(46.00 \mathrm{~g} \mathrm{C} /\left(\mathrm{m}^{2} \cdot \mathrm{a}\right)\right)$ while the annual grasses-annual forbs (An.grAn.fo) type had the lowest NPP value $\left(10.00 \mathrm{~g} \mathrm{C} /\left(\mathrm{m}^{2} \cdot \mathrm{a}\right)\right)$. The NPP was relatively high $(40.00 \mathrm{~g}$ $\left.\mathrm{C} /\left(\mathrm{m}^{2} \cdot \mathrm{a}\right)\right)$ in Daphne spp.-Astragalus spp. $(D a-A s)$ type with poor condition. Furthermore, degraded vegetation types and very poor rangelands (e.g., Gundelia spp.-Cousinia spp. (Gu-Co) and Sophora spp.-Launaea spp. (So-La)) had lower NPP values (18.00 and $19.00 \mathrm{~g} \mathrm{C} /\left(\mathrm{m}^{2} \cdot \mathrm{a}\right)$, respectively) compared to other shrublands. Generally, NPP values were different based on the vegetation cover and vegetation type. Accordingly, different observed NPP values were obtained for Astragalus spp.Acantholimon spp. (As-Ac; $\left.32.00 \mathrm{~g} \mathrm{C} /\left(\mathrm{m}^{2} \cdot \mathrm{a}\right)\right)$, Artemisia aucheri $\left(\right.$ Ar.au; $\left.29.00 \mathrm{~g} \mathrm{C} /\left(\mathrm{m}^{2} \cdot \mathrm{a}\right)\right)$, As-Da.F

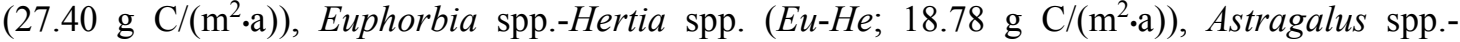
Cousinia spp. (As-Co; $\left.29.23 \mathrm{~g} \mathrm{C} /\left(\mathrm{m}^{2} \cdot \mathrm{a}\right)\right)$, and Astragalus spp.-Psathyrostachys spp. (As-Ps; 29.97 $\left.\mathrm{g} \mathrm{C} /\left(\mathrm{m}^{2} \cdot \mathrm{a}\right)\right)$.

The correlation between observed and estimated NPP values depended on vegetation types and rangeland conditions (Fig. 5). $A s-A g$ and $G u$-Co types had the highest (0.75) and lowest (0.36) correlation coefficients, respectively. Under similar rangeland conditions, An.gr-An.fo type showed a higher correlation coefficient compared to perennial plants. $A s-B r$ and $A s-D a$ rangelands with fair condition showed higher correlations between observed and estimated NPP values than those with poor condition. In general, higher correlations between observed and estimated NPP values were observed in rangeland areas with good condition. However, serious rangeland 
degradation and high spatial heterogeneity decreased the correlation between observed and estimated NPP values and the accuracy of the CASA model. In fact, remote (inaccessible) areas were healthier than grazed lands. Both the NPP and LUE of vegetation types used by livestock were low in rangelands near agricultural and residential areas as well as in rangelands with very poor condition. Due to the high level of spatial heterogeneity in these areas, lower correlations existed between observed and estimated NPP values (Fig. 5).

LUE values, which are used to evaluate the photosynthesis potential of different vegetation types, depend on vegetation types and rangeland conditions (Fig. 5). $A s-A g$ rangelands with good condition had the highest LUE $(0.117 \mathrm{~g} \mathrm{C} / \mathrm{MJ})$ and An.gr-An.fo rangelands with poor condition had the lowest LUE (0.010 $\mathrm{g} \mathrm{C} / \mathrm{MJ}) . A s-B r$ rangelands in fair condition had higher LUE values than those in poor condition. Generally, under poor rangeland condition, grass vegetation type showed higher LUE values than shrub vegetation. Moreover, Da-As (shrub form) had larger LUE values compared to bushlands (Fig. 5).

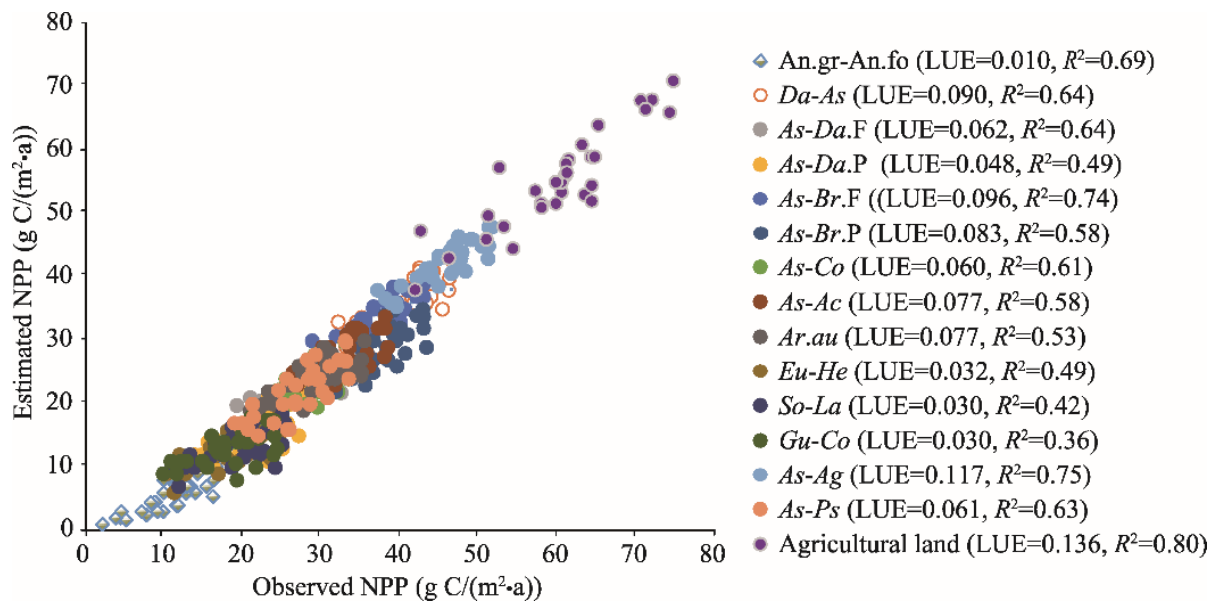

Fig. 5 Correlation between observed and estimated NPP values and light utilization efficiency (LUE) values in different vegetation types. An.gr-An.fo, annual grasses-annual forbs; Da-As, Daphne spp.-Astragalus spp.; As-Da.F and $A s-D a . P$, Astragalus spp.-Daphne spp. with fair and poor conditions, respectively; $A s-B r . \mathrm{F}$ and $A s-B r . \mathrm{P}$, Astragalus spp.-Bromus spp. with fair and poor conditions respectively; As-Co, Astragalus spp.-Cousinia spp.; AsAc, Astragalus spp.-Acantholimon spp.; Ar.au, Artemisia aucheri; Eu-He, Euphorbia spp.-Hertia spp.; So-La, Sophora spp.-Launaea spp.; Gu-Co, Gundelia spp.-Cousinia spp.; As-Ag, Astragalus spp.-Agropyron spp.; As-Ps, Astragalus spp.-Psathyrostachys spp..

Based on the 16-day MODIS composites, plant growth in the study area began in late March due to regional changes in climate. The regional NPP values ranged from 0.00 to $10.49 \mathrm{~g} \mathrm{C} /\left(\mathrm{m}^{2} \cdot \mathrm{a}\right)$ in March and 0.00 to $0.09 \mathrm{~g} \mathrm{C} /\left(\mathrm{m}^{2} \cdot \mathrm{a}\right)$ in September (Fig. 6). The production showed an increasing trend during 21 March-24 May. The maximum increase in NPP was observed during 8-24 May, a significant reduction in NPP $\left(0.00-0.82 \mathrm{~g} \mathrm{C} /\left(\mathrm{m}^{2} \cdot \mathrm{a}\right)\right)$ occurred during 24 May-9 June, and the parameter reached values of $0.00-0.09 \mathrm{~g} \mathrm{C} /\left(\mathrm{m}^{2} \cdot \mathrm{a}\right)$ on 13 September.

Comparison of the 16-day NPP and digital elevation model (DEM) maps revealed that NPP values depended on temperature conditions at the beginning of the growing season. Moreover, plant growth initially started from areas with lower altitudes. NPP values varied depending on the condition of the area at different times of the year, i.e., the topography of the area greatly influenced the spatial distribution of NPP. In March and April, the NPP values in rangelands located in plains, i.e., from $0.00-10.49 \mathrm{~g} \mathrm{C} /\left(\mathrm{m}^{2} \cdot \mathrm{a}\right)$ on 21 March (Fig. 6a) to $0.00-12.87 \mathrm{~g} \mathrm{C} /\left(\mathrm{m}^{2} \cdot \mathrm{a}\right.$ ) on 22 April (Fig. $6 \mathrm{c})$, were higher than the values in rangelands located in highlands. With arise in temperature in May, the NPP increased at highlands and reached the values of $0.00-21.92 \mathrm{~g} \mathrm{C} /\left(\mathrm{m}^{2} \cdot \mathrm{a}\right)$ for the whole study area during late May (Fig. 6e). However, with the beginning of the dry season and the considerable increase in temperature, the NPP values sharply declined to $0.00-0.82 \mathrm{~g} \mathrm{C} /\left(\mathrm{m}^{2} \cdot \mathrm{a}\right)$ on 9 June (Fig. 6f). Under such conditions, the highlands were more productive than the plains. In addition, the growth of different vegetation types decreased from highlands (lower temperature 

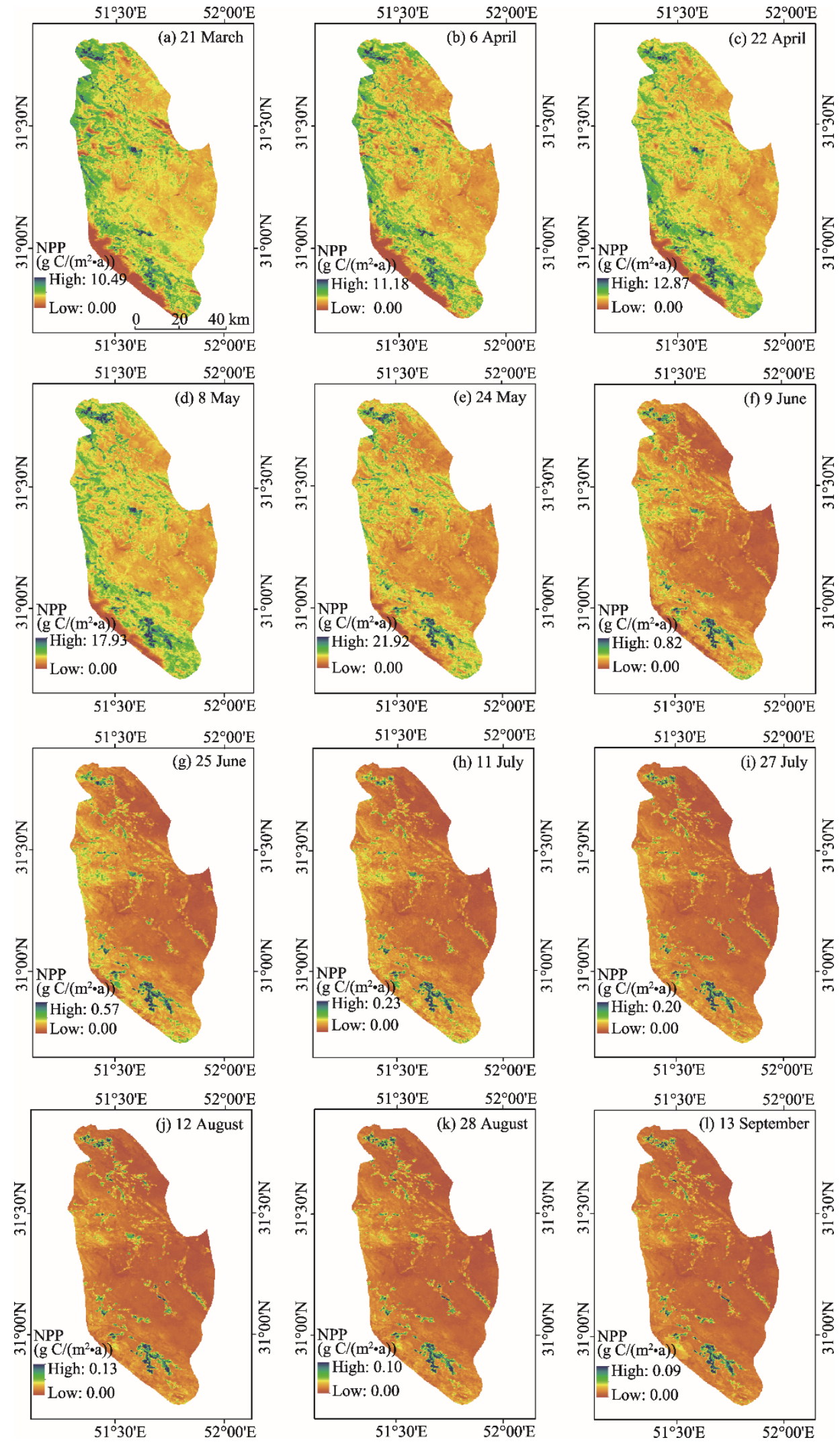

Fig. 6 Spatial and temporal distributions of NPP values based on the 16-day MODIS composites in 2016 
and higher humidity) to plains (higher temperature and lower humidity) and reached zero by late September.

In terms of spatial distribution, the western and southern parts of the study area generally had higher NPP values. During the growing season, rain-fed and agricultural lands had higher NPP values compared to grazed rangelands. Meanwhile, the rocky parts of the southern region had very low NPP values. Moreover, due to rangeland degradation, reduced NPP values were observed at the vicinity of Semirom County.

\subsection{Relationship between NPP changes and SPI}

The correlation between SPI and NPP changes depended on the vegetation types and rangeland conditions (Table 3). For the $A s-B r$ and $A s-D a$ vegetation types which had either poor or fair condition, higher correlations between SPI and NPP changes were detected in rangelands with fair condition than in rangelands with poor condition. Among different vegetation types, NPP changes in the An.gr-An.fo type had the greatest correlation $\left(R^{2}=0.86\right)$ with 1 -month SPI (SPI1). The correlation coefficients of NPP change with 2-, 3-, 6-, 9- and 12-month SPI were 0.83, 0.34, 0.24, 0.14 and 0.14 , respectively. It can be seen that these correlations sharply decreased in 6-, 9- and 12-month periods. Rangelands in very poor condition ( $\mathrm{So}-\mathrm{La}$ and $\mathrm{Gu}-\mathrm{Co}$ ) had the lowest correlation with SPI and the effect of short-term precipitation was more profound in these areas.

Table 3 Correlation coefficients of net primary production (NPP) changes and standardized precipitation index (SPI) at different time scales

\begin{tabular}{|c|c|c|c|c|c|c|}
\hline Vegetation type & SPI1 & SPI2 & SPI3 & SPI6 & SPI9 & SPI12 \\
\hline An.gr-An.fo & $0.86^{* *}$ & $0.83^{* * *}$ & $0.34^{*}$ & $0.24^{*}$ & 0.14 & 0.14 \\
\hline Arau & $0.70^{* * *}$ & $0.63^{* * *}$ & $0.58^{* *}$ & $0.53^{* *}$ & 0.23 & 0.23 \\
\hline$A s-A c$ & $0.72^{* * *}$ & $0.65^{* * *}$ & $0.54^{* *}$ & $0.50^{* *}$ & $0.28^{*}$ & $0.28^{*}$ \\
\hline$A s-A g$ & $0.83^{* * *}$ & $0.77^{* * *}$ & $0.56^{* *}$ & $0.46^{* *}$ & 0.14 & 0.14 \\
\hline$A s-B r . \mathrm{F}$ & $0.81^{* * *}$ & $0.75^{* * *}$ & $0.67^{* * *}$ & $0.63^{* * *}$ & $0.42^{* *}$ & $0.42^{* *}$ \\
\hline$A s-B r . \mathrm{P}$ & $0.79^{* * *}$ & $0.66^{* *}$ & $0.57^{* *}$ & $0.53^{* *}$ & 0.19 & 0.19 \\
\hline$A s-C o$ & $0.72^{* * *}$ & $0.70^{* *}$ & $0.55^{* *}$ & $0.50^{* *}$ & $0.31^{*}$ & $0.31^{*}$ \\
\hline$A s-D a . \mathrm{F}$ & $0.64^{* *}$ & $0.53^{* *}$ & $0.50^{* *}$ & $0.41^{* *}$ & $0.30^{*}$ & $0.30^{*}$ \\
\hline$A s-D a . \mathrm{P}$ & $0.58^{* *}$ & $0.51^{* *}$ & $0.46^{* *}$ & $0.38^{*}$ & $0.24^{*}$ & $0.24^{*}$ \\
\hline$A s-P s$ & $0.53^{* *}$ & $0.65^{* * *}$ & $0.60^{* *}$ & $0.55^{* *}$ & $0.41^{* * *}$ & $0.41^{* *}$ \\
\hline$D a-A s$ & $0.44^{* *}$ & $0.45^{* *}$ & $0.50^{* *}$ & $0.53^{* *}$ & $0.58^{* *}$ & $0.58^{* *}$ \\
\hline $\mathrm{Gu}-\mathrm{Co}$ & $0.50^{* *}$ & $0.39^{*}$ & $0.39^{*}$ & $0.31^{*}$ & 0.17 & 0.17 \\
\hline $\mathrm{Eu}-\mathrm{He}$ & $0.57^{* *}$ & $0.52^{* *}$ & $0.58^{* *}$ & 0.49 & 0.23 & 0.23 \\
\hline So-La & $0.55^{* *}$ & $0.41^{* *}$ & $0.36^{*}$ & 0.21 & 0.12 & 0.12 \\
\hline
\end{tabular}

Note: SPI1, 1-month SPI; SPI2, 2-month SPI; SPI3, 3-month SPI; SPI6, 6-month SPI; SPI9, 9-month SPI; SPI12, 12-month SPI. ${ }^{*},{ }^{* *}$ and ${ }^{* * *}$ represent significance at $P<0.05, P<0.01$ and $P<0.001$ levels, respectively.

Larger changes were observed in $A s-A g$ rangelands with grass-shrub composition and good condition than in rangelands with similar composition $(A s-B r)$ and fair condition. The effect of drought on NPP changes was low in degraded areas with very poor condition (Gu-Co and So-La). Drought in the growing season differently affected various vegetation types and rangeland conditions, i.e., the degraded vegetation type was the most sensitive to precipitation changes during the growing season. Generally, under the same rangeland conditions, shrub-bush $(D a-A s)$ plants were less sensitive to precipitation changes than bushes. In poor rangelands, 3-month SPI (SPI3) caused greater NPP changes in bushes than in annual plants. The correlation of NPP changes with SPI was higher in $A s-B r$ type (bush-grass form) than in bush types. Due to the lack of precipitation in June, July, August and September, the correlations of NPP changes with 9- and 12-month SPI were completely identical. Moreover, in all vegetation types, the correlation between NPP changes and 1-month SPI was significant at 5\% significance level. The correlations were significant at $1 \%$ level in bush-grass types ( $A s-B r$ and $A s-A g$ ) and annual plants (An.gr-An.fo) with good and fair 
conditions.

\subsection{NPP changes during the drought and wet periods}

We calculated NPP changes in the drought (2013-2016) and wet (2004-2007) periods based on the SPI (Fig. 7). During the 4-year wet period (2004-2007), the NPP showed an average increase of $0.75 \mathrm{~g} \mathrm{C} /\left(\mathrm{m}^{2} \cdot \mathrm{a}\right)$ in the study area. The magnitude of changes depended on vegetation types and rangeland conditions. During this period, the NPP of An.gr-An.fo and the dominant shrub type ( $D a-$ $A s)$ showed the highest $\left(2.01 \mathrm{~g} \mathrm{C} /\left(\mathrm{m}^{2} \cdot \mathrm{a}\right)\right)$ and lowest $\left(0.52 \mathrm{~g} \mathrm{C} /\left(\mathrm{m}^{2} \cdot \mathrm{a}\right)\right)$ levels of increase, respectively. Furthermore, the changes of NPP were larger in bush-grass type than in bush type (Fig. 7).

The total NPP in all studied vegetation types decreased by an average of $1.03 \mathrm{~g} \mathrm{C} /\left(\mathrm{m}^{2} \cdot \mathrm{a}\right)$ within the 4-year drought period (2013-2016). The highest reduction $\left(1.73 \mathrm{~g} \mathrm{C} /\left(\mathrm{m}^{2} \cdot \mathrm{a}\right)\right)$ was observed in An.gr-An.fo while the lowest reduction $\left(0.25 \mathrm{~g} \mathrm{C} /\left(\mathrm{m}^{2} \cdot \mathrm{a}\right)\right)$ in shrub-bush type $(D a-A s)$. NPP reductions were more pronounced in very poor rangelands than in poor and fair rangelands. Although the NPP of rangelands around residential areas did not show a significant increase during the wet period (2004-2007), it had a more profound reduction $\left(3.00 \mathrm{~g} \mathrm{C} /\left(\mathrm{m}^{2} \cdot \mathrm{a}\right)\right)$ during the drought period (2013-2016).

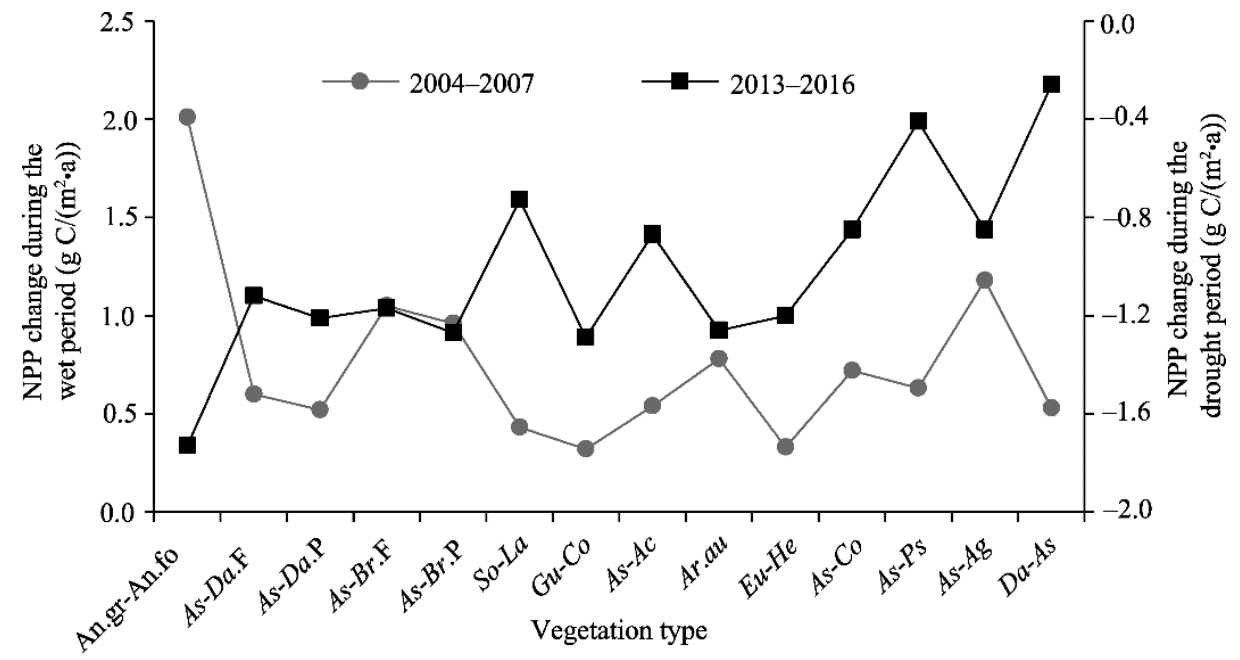

Fig. 7 Changes of NPP in relation to standardized precipitation index (SPI) during the wet (2004-2007) and drought (2013-2016) periods

\section{Discussion}

The results in this study showed that the CASA model was very reliable and had a great potential for studying the spatial and temporal dynamics of NPP in the semi-arid rangelands of Semirom County, Iran. Our research demonstrated a 95\% correlation between observed and estimated NPP values over the whole study area. Since the CASA works based on the exact determination of LUE values (Yu et al., 2009) and the accurate estimation of LUE, thus, the high accuracy of the model can be attributed to the appropriate number of sampling sites, exact classification of rangeland conditions and vegetation types in the study area, and to the appropriateness of the sampling size in relation to the extent of the study.

According to the correlations between observed and estimated NPP values, the NPP map did not have similar accuracy in all vegetation types. Despite the small LUE values, the observed NPP value in An.gr-An.fo type was highly correlated with the estimated NPP value $\left(R^{2}=0.69\right)$. Furthermore, under different rangeland conditions, the $A s-D a\left(R^{2}=0.64\right.$ in fair rangelands and $R^{2}=0.49$ in poor rangelands) and $A s-B r\left(R^{2}=0.74\right.$ in fair rangelands and $R^{2}=0.58$ in poor rangelands) had different correlations between observed and estimated NPP values (Fig. 5).

In addition, a greater heterogeneity of plant and bare soil (patch and interpatch) was observed in 
bushlands than in lands with annual herbs and shrub-grass. This affected the sampled data and decreased the homogeneity and plant vitality in degraded areas (Li et al., 2011). Therefore, the low correlation between observed and estimated NPP values in degraded vegetation types could have been caused by the reduced level of correlation between field and remotely sensed data in degraded areas and the sampling error due to the plant distribution pattern in shrublands compared to annual plant types. Previous research has also confirmed the role of plant distribution pattern and regional heterogeneity in sampling accuracy and the effects of plant characteristics in the correlation between field and remotely sensed data (Goldsmith, 1991). While the CASA uses the NDVI, the values of this index can vary or decrease due to the unique properties of each vegetation type, which is determined by the plant species, soil, and physiography of the area. Such a difference or reduction can be another reason for the decreased accuracy of the CASA model in NPP estimation and it seems to have greater effects in degraded areas with low vegetation canopies (Jafari et al., 2007).

The level of correlations between observed and estimated NPP values at the sampling sites could be influenced by different sources of error. For example, the field production data were collected over several days, and the remotely sensed imagery captured landscape conditions at a particular point of time. Consequently, temporal variations in rangeland production resulting from continuous grazing and changes in weather conditions must be considered as contributors to the variability in the field data. In addition, the slight mismatch between the exact area sampled in the field and the pixels extracted from the imagery could also potentially reduce the strength of the relationships between the two datasets. Finally, the field data were measured by several field workers, which added another source of potential variation to the data. It has been previously shown that there may be up to $20 \%$ difference in the measurements of field data obtained by experienced field workers, using objective methods similar to the double sampling approach (Friedel and Shaw, 1987; Wilson et al., 1987). The amount of NPP varied from one vegetation type to another. The lowest (10.00 g $\left.\mathrm{C} /\left(\mathrm{m}^{2} \cdot \mathrm{a}\right)\right)$ and highest $\left(46.00 \mathrm{~g} \mathrm{C} /\left(\mathrm{m}^{2} \cdot \mathrm{a}\right)\right)$ NPP values belonged to An.gr-An.fo and $A s-A g$ types, respectively. The role of plant physiology (e.g., vegetation form and leaf area index) in water use efficiency and production could potentially be responsible for this finding. In addition, regional plant composition can affect water penetration (Caylor and Shugart, 2004). Although trees and shrubs have deeper roots than bushes, grasses and annual plants have the highest sensitivity to drought and low contents of soil nutrients. This sensitivity can considerably affect the production and efficiency of plants (Throop et al., 2012). The $D a-A s$ (shrub-bush lands) had higher NPP values than the species in bushlands, probably due to the latter's high ability to use deep soil moisture. Rangelands in very poor condition had lower NPP values, which may be due to their degraded soil structure, reduced soil organic and inorganic matter contents, and decreased soil moisture. The soil had more desirable properties (e.g., absorbable moisture and nutrients) in rangelands with better conditions such as $A s-A g$ rangelands (Zika and Erb, 2009). Plant species, vegetation forms, soil types and conditions (Schlesinger and Andrews, 2000), plant distribution pattern (Stephenson, 1990), and exploitation history (Zhang et al., 2007) are generally considered as factors affecting the efficiency and NPP of vegetation types.

LUE assessments in different rangeland types showed that LUE depended on vegetation types and rangeland conditions. In this study, the highest and lowest values of LUE were found in $A s-A g$ (0.117 g C/MJ) and An.gr-An.fo (0.010 g C/MJ), respectively (Fig. 5). Therefore, the interaction between climatic and physiological factors in plant species seems to be responsible for LUE changes. In semi-arid areas, shrubs and bushes have higher drought resistance due to their woody stems, deep roots and low evapotranspiration. Hence, these plants have higher photosynthetic efficiency and could produce greater annual biomass compared to annual plants (Whitehead and Gower, 2001). Since rangeland condition changes can alter photosynthetic efficiency in a vegetation type, rangeland degradation decreased both the LUE and NPP values in similar vegetation types (e.g., $A s-D a$ ).

During the growing season, plants can have different production rates depending on changes in temperature and humidity, i.e., plants start to germinate at the beginning of the growing season (when the base temperature is reached) and the growth rate increases with the increase of temperature and precipitation. The growing season in the study area began on $21 \mathrm{March}$. The NPP 
peaked around 24 May and started to decrease on 9 June. Observations have shown that when the required moisture is accessible by the vegetation, plant production maximizes in optimal temperature. The growth rate decreases and stops as the temperature starts to rise (Clark et al., 2003). Increased leaf area index in the middle of the growing season has been identified as another reason for improving the productivity of plants (Roupsard et al., 2009). The CASA considers optimum conditions and soil moisture content, and calculates NPP values based on changes in temperature (Potter, 2012a). According to the results of the present study, this model can be used to calculate seasonal NPP values in different vegetation types at regional levels. This finding is in line with seasonal weather changes and the findings of previous study (Potter et al., 2012b). Thus, the estimation of NPP (for various applications) is possible based on daily growth rates and climatic parameters at various phases of plant phenology (Cuadra et al., 2012).

Annual evaluations highlighted the major effects of precipitation on NPP. Although drought conditions (2013-2016) reduced NPP levels in all vegetation types throughout the study area, the NPP increased during the wet period (2004-2007) (Fig. 7). The results indicated a strong correlation between SPI and NPP changes in all vegetation types (Table 3). Studies in semi-arid regions have reported that precipitation affects the NPP of plants through its effects on soil moisture (Chen et al., 2013). This might be caused by the effects of drought on leaf area index, as a determinant of changes in NPP. In fact, long-term and repeated periods of drought could reduce the carbohydrate storage of plants and impair their physiological balance. Consequently, the plants will be unable to increase production even in wet periods (Holechek et al., 1989). Additionally, due to the fragility of the ecosystems in semi-arid areas compared to humid areas, drought periods have more destructive effects on plants. Such effects will be more intense in degraded areas (Lei et al., 2015). Therefore, drought is considered as the most important climatic factor controlling plant production and carbon cycle in semi-arid regions (Peng et al., 2015). Large annual fluctuations in plant production are also observed in these areas (Wessels et al., 2007).

An.gr-An.fo plants exhibit better responses to short-term and repeated precipitation due to their root structures. Shrub-bush plants (e.g., $A s-D a$ ) have different root structures and woody stems which make the species less sensitive to long periods without precipitation, i.e., they have a higher drought-tolerance than grasses. Consequently, SPI had larger correlations with NPP in $A s-A g$ and $A s-B r$ plants than in species of bushlands. NPP was less sensitive to climate in the shrub-bush type $(D a-A s)$ than in bush type. Previous studies have also reported similar findings (O'connor and Roux, 1995; Xu et al., 2013). According to previous studies, due to destructed soil structure, decreased soil permeability and reduced vegetation canopy, the effect of precipitation on NPP decreases and the runoff increases in poor and very poor rangelands (Gao et al., 2013).

High seasonal fluctuations in precipitation were observed in the study area. In fact, precipitation mainly occurred during the cold seasons and amounted to zero (in some parts) as the temperature rose at the beginning of the warm seasons. As a result, plant growth declined and phenological stages gradually stopped in the warm seasons. Moreover, since the plants could not grow with temperature fall during the cold seasons (until late March), their growth period was limited to the interval between 21 March and the first week of June (Fig. 6). These factors decreased NPP in semi-arid regions (Fridley et al., 2016). Low temperatures and delayed plant phenological stages at highlands reduced NPP values in the early growing season (Fig. 6). Therefore, exploitation of these areas in the early growing season disturbs plant physiology balance and leads to soil erosion (Wang et al., 2017).

The CASA model uses monthly precipitation data to measure soil moisture. However, shrubs and bushes can use deep soil moisture for a long time due to their root structure. The model was, hence, more accurate in estimating NPP in the annual plant types. Although soil moisture is the most important determinant of NPP in semi-arid areas, it only ranges between 0 and 1 in the CASA model. Consequently, parameters in the CASA model need to be revised for semi-arid areas.

\section{Conclusions}

The CASA model applied in this research could estimate NPP in semi-arid rangelands of Iran with 
a high accuracy at the regional scale. The results suggested that vegetation types (vegetation forms and plant species), rangeland conditions and regional topography affected the LUE values and thus the accuracy of the CASA model. The correlations between NPP changes and SPI indicated that within a particular region, NPP values differed depending on plant species, vegetation forms and rangeland conditions. Annual plants and shrubs respectively showed the highest and lowest sensitivity to drought variations. Moreover, the effects of seasonal distribution pattern of precipitation on NPP varied in different plant species. The effects of drought and wet periods on NPP were determined by rangeland conditions and the local characteristics of the region, i.e., degraded areas and areas near villages were mostly damaged by drought and were less likely to be restored during the wet periods. Furthermore, NPP values were decreased in the study area where the growing season was limited to a few months due to the low temperatures in the cold seasons and the lack of precipitation in the warm seasons.

The results of this study confirmed the applicability of the CASA model for the estimation of NPP in rangeland vegetation types at different spatial and temporal scales. CASA modeling can facilitate the assessment of rangeland readiness based on NPP values and the determination of rangeland capacity for various utilizations such as grazing and wildlife use. In addition, rangeland degradation processes in various vegetation types can be studied by NPP evaluations. Therefore, this study recommends the application of the CASA model for the evaluation and monitoring of wide rangelands in Iran (covering over $52 \%$ of the country). The model outputs provide up-to-date and valuable information on plant production that can be used for reporting rangeland conditions.

\section{References}

Alamdari P, Nematollahi O, Alemrajabi A A. 2013. Solar energy potentials in Iran: A review. Renewable and Sustainable Energy Reviews, 21: 778-788.

Ardö J, Tagesson T, Jamali S, et al. 2018. MODIS EVI-based net primary production in the Sahel 2000-2014. International Journal of Applied Earth Observation and Geoinformation, 65: 35-45.

Bao G, Bao Y H, Qin Z H, et al. 2016. Modeling net primary productivity of terrestrial ecosystems in the semi-arid climate of the Mongolian Plateau using LSWI-based CASA ecosystem model. International Journal of Applied Earth Observation and Geoinformation, 46: 84-93.

Biondini M E, Patton B D, Nyren P E. 1998. Grazing intensity and ecosystem processes in a northern mixed-grass prairie, USA. Ecological Applications, 8(2): 469-479.

Bonham C D. Measurement for Terrestrial Vegetation. Hoboken: John Wiley \& Sons, 338.

Caylor K K, Shugart H H. 2004. Simulated productivity of heterogeneous patches in Southern African savanna landscapes using a canopy productivity model. Landscape Ecology, 19(4): 401-415.

Chen G, Tian H, Zhang C, et al. 2012. Drought in the Southern United States over the $20^{\text {th }}$ century: variability and its impacts on terrestrial ecosystem productivity and carbon storage. Climatic Change, 114(2): 379-397.

Chen T, Van der Werf G R, De Jeu R A M, et al. 2013. A global analysis of the impact of drought on net primary productivity. Hydrology and Earth System Sciences, 17: 3885-3894.

Chen T, Huang Q H, Liu M, et al. 2017. Decreasing net primary productivity in response to urbanization in Liaoning Province, China. Sustainability, 9(2): 162, doi: 10.3390/su9020162.

Clark D A, Piper S C, Keeling C D, et al. 2003. Tropical rain forest tree growth and atmospheric carbon dynamics linked to interannual temperature variation during 1984-2000. Proceedings of the National Academy of Sciences of the United States of America, 100(10): 5852-5857.

Cuadra S V, Costa M H, Kucharik C J, et al. 2012. A biophysical model of sugarcane growth. Global Change Biolagy Bioenergy, 4(1): $36-48$.

Dannenberg M P, Song C, Hwang T, et al. 2015. Empirical evidence of El Niño-Southern Oscillation influence on land surface phenology and productivity in the western United States. Remote Sensing of Environment, 159: 167-180.

Dieguez H, Paruelo J M. 2017. Disentangling the signal of climatic fluctuations from land use: changes in ecosystem functioning in South American protected areas (1982-2012). Remote Sensing in Ecology and Conservation, 3(4): 177-189.

Dintwe K, Okin G S. 2018. Soil organic carbon in savannas decreases with anthropogenic climate change. Geoderma, 309: 7-16.

Dong G T, Bai J, Yang S T, et al. 2015. The impact of land use and land cover change on net primary productivity on China's Sanjiang Plain. Environmental Earth Sciences, 74(4): 2907-2917. 
Donmez C, Berberoglu S, Curran P J. 2011. Modelling the current and future spatial distribution of NPP in a Mediterranean watershed. International Journal of Applied Earth Observation and Geoinformation, 13(3): 336-345.

Feizi M T. 2018. Ecological Regions of Iran Vegetation Types of Isfahan Province. Tehran: Research Institute of Forests and Rengelands, 290.

Fischer D G, Chapman S K, Classen A T, et al. 2014. Plant genetic effects on soils under climate change. Plant and Soil, 379(12): $1-19$.

Fridley J D, Lynn J S, Grime J P, et al. 2016. Longer growing seasons shift grassland vegetation towards more-productive species. Nature Climate Change, 6: 865-868.

Friedel M H, Shaw K. 1987. Evaluation of methods for monitoring sparse patterned vegetation in arid rangelands. I. Herbage. Journal of Environmental Management, 25(4): 309-318.

Friedel M H. 1991. Range condition assessment and the concept of thresholds: A viewpoint. Journal of Range Management, 44(5): 422-426.

Gao Q Z, Wan Y F, Li Y, et al. 2013. Effects of topography and human activity on the net primary productivity (NPP) of alpine grassland in northern Tibet from 1981 to 2004. International Journal of Remote Sensing, 34(6): 2057-2069.

Goetz S J, Prince S D, Goward S N, et al. 1999. Satellite remote sensing of primary production: an improved production efficiency modeling approach. Ecological Modelling, 122(3): 239-255.

Goldsmith F B. 1991. Monitoring for Conservation and Ecology. Virginia Beach: Chapman \& Hall Press, 275.

Hadian F, Jafari R, Bashari H. 2013. Assessing the accuracy of spectral indices in vegetation cover mapping at vegetation type and across vegetation type scales, using TM sensor data in southern Zagros regions. Iranian Remote Sensing and GIS, 4(4): 83-100.

Holechek J L, Pieper R D, Herbel C H. 1989. Range Management. Principles and Practices. New Jersey: Prentice Hall Press, 526.

Hua L Z, Liu H, Zhang X L, et al. 2014. Estimation terrestrial net primary productivity based on CASA Model: a case study in Minnan urban agglomeration, China. IOP Conference Series: Earth and Environmental Science. IOP Publishing, 012153, doi: $10.1088 / 1755-1315 / 17 / 1 / 012153$.

IRIMO. 2016. Islamic republic of Iran meteorological organization (IRIMO). [2016-06-29]. http://www.irimo.ir/eng/index.php.

Jafari R, Lewis M M, Ostendorf B. 2007. Evaluation of vegetation indices for assessing vegetation cover in southern arid lands in South Australia. The Rangeland Journal, 29(1): 39-49.

Jafari R, Bakhshandehmehr L. 2013. Quantitative mapping and assessment of environmentally sensitive areas to desertification in central Iran. Land Degradation \& Development, 27(2): 108-119.

Jay S, Potter C, Crabtree R, et al. 2016. Evaluation of modelled net primary production using MODIS and landsat satellite data fusion. Carbon Balance and Management, 11: 8, doi: 10.1186/s13021-016-0049-6.

Ji L, Peters A J. 2003. Assessing vegetation response to drought in the northern Great Plains using vegetation and drought indices. Remote Sensing of Environment, 87(1): 85-98.

Jiang C, Wu Z F, Cheng J, et al. 2015. Impacts of urbanization on net primary productivity in the Pearl River Delta, China. International Journal of Plant Production, 9(4): 581-598.

Kaminski T, Knorr W, Rayner P J, et al. 2002. Assimilating atmospheric data into a terrestrial biosphere model: A case study of the seasonal cycle. Global Biogeochemical Cycles, 16(4): 14-1-14-16.

Kehl M. 2009. Quaternary climate change in Iran-the state of knowledge. Erdkunde, 63(1): 1-17.

Khajeddin S J. 1995. A survey of the plant communities of the Jazmorian, Iran, using Landsat MSS data. Ph.D Thesis. UK: University of Reading.

Khaleghi M R, Aeinebeygi S. 2016. An assessment of biennial enclosure effects on range production, condition and trend (case study: Taftazan rangeland, Shirvan). International Journal of Forest, Soil and Erosion (IJFSE), 6(2): 33-40.

Khatibi R, Soltani S, Khodagholi M. 2017. Effects of climatic factors and soil salinity on the distribution of vegetation types containing Anabasis aphylla in Iran: a multivariate factor analysis. Arabian Journal of Geosciences, 10(2): 36, doi: 10.1007/s12517-016-2812-0.

Kimball J S, White M A, Running S W. 1997. BIOME-BGC simulations of stand hydrologic processes for BOREAS. Journal of Geophysical Research, 102(D24): 29043-29051.

Lammers J M, Schubert C J, Middelburg J J, et al. 2017. Microbial carbon processing in oligotrophic Lake Lucerne (Switzerland): results of in situ ${ }^{13} \mathrm{C}$-labelling studies. Biogeochemistry, 136(2): 131-149.

Lei T J, Wu J J, Li X H, et al. 2015. A new framework for evaluating the impacts of drought on net primary productivity of grassland. Science of The Total Environment, 536: 161-172.

Li W, Huang H Z, Zhang Z N, et al. 2011. Effects of grazing on the soil properties and C and N storage in relation to biomass allocation in an alpine meadow. Journal of Soil Science and Plant Nutrition, 11(4): 27-39. 
Liang W, Yang Y T, Fan D M, et al. 2015. Analysis of spatial and temporal patterns of net primary production and their climate controls in China from 1982 to 2010. Agricultural and Forest Meteorology, 204: 22-36.

Lloyd-Hughes B, Saunders M A. 2002. A drought climatology for Europe. International Journal of Climatology, 22(13): 15711592.

Lokupitiya E, Denning S, Paustian K, et al. 2009. Incorporation of crop phenology in Simple Biosphere Model (SiBcrop) to improve land-atmosphere carbon exchanges from croplands. Biogeosciences, 6(6): 969-986.

Lu Q S, Gao Z Q, Ning J C, et al. 2015. Impact of progressive urbanization and changing cropping systems on soil erosion and net primary production. Ecological Engineering, 75: 187-194.

McCoy R M. 2005. Field Methods in Remote Sensing. New York: Guilford Press, 575.

Nemry B, FrançOis L, Gérard J C, et al. 1999. Comparing global models of terrestrial net primary productivity (NPP): analysis of the seasonal atmospheric $\mathrm{CO}_{2}$ signal. Global Change Biology, 5(S1): 65-76.

O'connor T G, Roux P W. 1995. Vegetation changes (1949-71) in a semi-arid, grassy dwarf shrubland in the Karoo, South Africa: influence of rainfall variability and grazing by sheep. Journal of Applied Ecology, 32(3): 612-626.

Pan G, Sun G J, Li F M. 2009. Using QuickBird imagery and a production efficiency model to improve crop yield estimation in the semi-arid hilly Loess Plateau, China. Environmental Modelling \& Software, 24(4): 510-516.

Peng J, Loew A, Zhang S Q, et al. 2015. Spatial downscaling of satellite soil moisture data using a vegetation temperature condition index. Geoscience and Remote Sensing, IEEE Transactions on Geoscience and Remote Sensing, doi: 10.1109/TGRS.2015.2462074.

Potter C S, Klooster S, Brooks V. 1999. Interannual variability in terrestrial net primary production: exploration of trends and controls on regional to global scales. Ecosystems, 2(1): 36-48.

Potter C. 2012a. Net primary production and carbon cycling in coast redwood forests of central California. Open Journal of Ecology, 2(3): 147-153.

Potter C, Klooster S, Genovese V. 2012b. Net primary production of terrestrial ecosystems from 2000 to 2009. Climatic Change, 115(2): 365-378.

Rafique R, Xia J Y, Hararuk O, et al. 2017. Comparing the performance of three land models in global C cycle simulations: A detailed structural analysis. Land Degradation \& Development, 28(2): 524-533.

Rohli R V, Vega A J. 2013. Climatology. Burlinton: Jones \& Bartlett Publishers, 451.

Roupsard O, Le Maire G L, Nouvellon Y, et al. 2009. Scaling-up productivity (NPP) using light or water use efficiencies (LUE, WUE) from a two-layer tropical plantation. Agroforestry Systems, 76(2): 409-422.

Roxburgh S H, Berry S L, Buckley T N, et al. 2005. What is NPP? Inconsistent accounting of respiratory fluxes in the definition of net primary production. Functional Ecology, 19(3): 378-382.

Ruimy A, Saugier B, Dedieu G. 1994. Methodology for the estimation of terrestrial net primary production from remotely sensed data. Journal of Geophysical Research: Atmospheres, 99(D3): 5263-5283.

Sainte-Marie J, Henrot A, Barrandon M, et al. 2012. Modeling the environmental and seasonal influence on canopy dynamic and litterfall of even-aged forest ecosystems by a model coupling growth \& yield and process-based approaches. In: 2012 IEEE $4^{\text {th }}$ International Symposium on Plant Growth Modeling, Simulation, Visualization and Applications. Shanghai, China: IEEE, 324-331.

Schimel D S, Braswell B H, Holland E A, et al. 1994. Climatic, edaphic, and biotic controls over storage and turnover of carbon in soils. Global Biogeochemical Cycles, 8(3): 279-293.

Schlesinger W H, Andrews J A. 2000. Soil respiration and the global carbon cycle. Biogeochemistry, 48(1): 7-20.

Sha Z, Xie Y, Tan X, et al. 2017. Assessing the impacts of human activities and climate variations on grassland productivity by partial least squares structural equation modeling (PLS-SEM). Journal of Arid Land, 9 (4): 473-488.

Stephenson N L. 1990. Climatic control of vegetation distribution: the role of the water balance. The American Naturalist, 135(5): 649-670.

Stoddart L, Smith A, Box T. 1975. Range Management (3 $3^{\text {rd }}$ ed.) . New York: McGraw-Hill Book Company, 433.

Sun Z G, Long X H, Sun C M, et al. 2013. Evaluation of net primary productivity and its spatial and temporal patterns in southern China's grasslands. The Rangeland Journal, 35(3): 331-338.

Throop H L, Reichmann L G, Sala O E, et al. 2012. Response of dominant grass and shrub species to water manipulation: an ecophysiological basis for shrub invasion in a Chihuahuan Desert grassland. Oecologia, 169(2): 373-383.

Wang S Y, Zhang B, Yang Q C, et al. 2017. Responses of net primary productivity to phenological dynamics in the Tibetan Plateau, China. Agricultural and Forest Meteorology, 232: 235-246.

Wessels K J, Prince S D, Malherbe J, et al. 2007. Can human-induced land degradation be distinguished from the effects of rainfall variability? A case study in South Africa. Journal of Arid Environments, 68(2): 271-297. 
Whitehead D, Gower S T. 2001. Photosynthesis and light-use efficiency by plants in a Canadian boreal forest ecosystem. Tree Physiology, 21(12-13): 925-929.

Wilson A D, Abraham N A, Barratt R, et al. 1987. Evaluation of methods of assessing vegetation change in the semi-arid rangelands of southern Australia. The Rangeland Journal, 9(1): 5-13.

Xia J Y, Luo Y Q, Wang Y P, et al. 2013. Traceable components of terrestrial carbon storage capacity in biogeochemical models. Global Change Biology, 19(7): 2104-2116.

Xu X, Sherry R A, Niu S L, et al. 2013. Net primary productivity and rain-use efficiency as affected by warming, altered precipitation, and clipping in a mixed-grass prairie. Global Change Biology, 19(9): 2753-2764.

Yeganeh H, Khajedein S J, Amiri F, et al. 2014. Monitoring rangeland ground cover vegetation using multitemporal MODIS data. Arabian Journal of Geosciences, 7(1): 287-298.

Yu D Y, Yang M C, Pan Y Z, et al. 2005. Study on temporal and spatial changes of light utilization efficiency (LUE) for vegetations in Eastern Asia. In: 2005 IEEE Geoscience and Remote Sensing Symposium, 2005. IGARSS'05. Seoul, South Korea: IEEE, 1896-1899.

Yu D Y, Shi P J, Shao H B, et al. 2009. Modelling net primary productivity of terrestrial ecosystems in East Asia based on an improved CASA ecosystem model. International Journal of Remote Sensing, 30(18): 4851-4866.

Yu R, Evans A J, Malleson N. 2018. Quantifying grazing patterns using a new growth function based on MODIS Leaf Area Index. Remote Sensing of Environment, 209: 181-194.

Yuan J G, NIU Z, WANG C L.2006. Vegetation NPP distribution based on MODIS data and CASA Model-a case study of northern Hebei Province. Chinese Geographical Science, 16(4): 334-341.

Zhang L, Zhou G S, Ji Y H, et al. 2017. Grassland carbon budget and its driving factors of the subtropical and tropical monsoon region in China during 1961 to 2013. Scientific Reports, 7: 14717, doi: 10.1038/s41598-017-15296-7.

Zhang L X, Zhou D C, Fan J W, et al. 2015. Comparison of four light use efficiency models for estimating terrestrial gross primary production. Ecological Modelling, 300: 30-39.

Zhang N, Yu Z L, Yu G R, et al. 2007. Scaling up ecosystem productivity from patch to landscape: a case study of Changbai Mountain Nature Reserve, China. Landscape Ecology, 22(2): 303-315.

Zhou W, Gang C C, Zhou F C, et al. 2015. Quantitative assessment of the individual contribution of climate and human factors to desertification in northwest China using net primary productivity as an indicator. Ecological Indicators, 48: 560-569.

Zika M, Erb K H. 2009. The global loss of net primary production resulting from human-induced soil degradation in drylands. Ecological Economics, 69(2): 310-318. 